\title{
Positive Personality Features and Stress among First-year University Students: Implications for Psychological Distress, Functional Impairment, and Self-esteem
}

\author{
Avi Besser $^{1}$ and Virgil Zeigler-Hill ${ }^{2}$ \\ ${ }^{1}$ Department of Behavioral Sciences and Center for Research in Personality, Life \\ Transitions, and Stressful Life Events, Sapir Academic College, D. N. Hof \\ Ashkelon, Israel \\ ${ }^{2}$ Department of Psychology, Oakland University, Rochester, MI, USA
}

The transition to college has often been treated as a period that creates considerable stress in the lives of students and it has been found to increase their distress and lower their self-esteem. The purpose of the present study was to examine whether the positive personality features of optimism, hope, and happiness were associated with the levels of psychological distress (i.e., perceived stress, depressive symptoms, and anxiety), functional impairment, and self-esteem reported by 217 freshman university students in Israel during the course of their first semester. A three-wave longitudinal study was used to examine whether positive personality features measured during the first week of the semester (Time-1) were associated with subsequent assessments of psychological distress, functional impairment, and self-esteem that took place during the third (Time-2) and fifteenth weeks (Time-3) of the semester. Results indicated a significant increase in distress symptoms and functional impairment during the course of the semester. Further, positive personality features at Time-1 were associated with levels of psychological distress, functional impairment, and self-esteem at Time-3 and these connections were mediated by Time- 2 assessments. Moreover, results indicated that psychological distress at Time-2 was associated with greater distress, more functional impairment, and lower selfesteem at Time-3. Discussion will focus on the extent to which positive personality features offer protection from the deleterious consequences of stress and the possibility that psychological distress deteriorates personal resources.

Keywords: Optimism; Hope; Happiness; Self-esteem; Positive; Distress; Stress; Functional impairment; Depression; State anxiety.

Life changes and transitions often serve as stressors because they foster the perception that environmental demands exceed the capacity of individuals to cope

Received 8 June 2012; accepted 28 September 2012; first published online 24 October 2012.

Correspondence should be addressed to: Avi Besser, Department of Behavioral Sciences and Center for Research in Personality, Life Transitions, and Stressful Life Events, Sapir Academic College, D. N. Hof Ashkelon 79165, Israel. E-mail: besser@mail.sapir.ac.il or to Virgil Zeigler-Hill, Department of Psychology, Oakland University, 212A Pryale Hall, Rochester, MI 48309, USA. E-mail: zeiglerh@oakland.edu

We would like to acknowledge research assistants at Sapir Academic College, Israel and Ben Gurion University of the Negev Eilat Campus, Israel, for their valuable assistance during data collection. We would also like to thank all of the participants in this study, as well as the anonymous reviewers for their constructive suggestions and comments on an earlier draft of this paper. 
with these demands (e.g., Lazarus \& Folkman, 1984; Malach-Pines \& Keinan, 2007; Vermunt \& Steensma, 2005). These stressful situations have been found to produce a wide range of negative consequences for mental health including anxiety and depressive symptoms (e.g., Vinokur \& Selzer, 1975; see Wheaton, 1990, for a review). The goal of the present study was to examine whether positive personality features offer some degree of protection from the negative consequences of stress. Our interest in positive personality features stems from the fact that these characteristics have the potential to shape how individuals perceive events as well as how they respond to these events. That is, certain positive personality features may share common features - such as the ability to identify the positive elements of negative experiences - that allow individuals to deal more effectively with stressful situations (Affleck \& Tennen, 1996). We expected that individuals with positive personality features would report less psychological distress than other individuals during a potential stressful transition period in their lives because these characteristics would allow them to maintain positive expectations about the event and its eventual outcome (e.g., Cann \& Etzel, 2008; Cann, Stilwell, \& Taku, 2010).

Strengths of character are among the central concerns of positive psychology (McCullough \& Snyder, 2000; Seligman, 2002; Seligman, \& Csikszentmihalyi, 2000). Character strengths can be defined as positive features that are reflected in the thoughts, feelings, and behaviors of individuals (e.g., Park, Peterson, \& Seligman, 2004). Based on recent studies concerning positive personality features (e.g., Cann \& Etzel, 2008; Cann et al., 2010), we decided to focus our attention on the dispositional aspects of optimism, hope, and happiness because these characteristics have been shown to influence how individuals perceive and respond to potential stressors. Optimism refers to the general belief that positive outcomes are likely to occur (Carver, Scheier, \& Miller, 2009; Scheier \& Carver, 1985). Individuals who report high levels of optimism tend to reframe situations in positive ways that allow them to see the best in relatively bad situations (Carver, Scheier, \& Weintraub, 1989; Scheier \& Carver 1985). Optimism has consistently been found to be associated with more positive responses to life stressors (e.g., Carver \& Scheier, 2001; Carver, Scheier, \& Segerstrom, 2010). Hope involves the belief that an individual will be able to find a way to reach his or her goals (C. Snyder, 2000; C. Snyder, Rand, \& Sigmon, 2002). Hope has a cognitive basis that concerns information and goals but it also has a motivational quality (Folkman, 2010). Although individuals who tend to experience higher levels of hope have been found to report greater positive affect, hope is most often considered to be a state of mind rather than an emotion per se. The tendency to experience hope has been found to be associated with positive responses to stressful situations (e.g., Affleck \& Tennen, 1996; Folkman, 2010). Happiness is a personality variable that refers to the extent to which individuals are satisfied with their lives (Diener, 2000; Lyubomirsky \& Lepper, 1999; Seligman, 2002). Happy individuals tend to interpret life events in a positive manner (Seidlitz \& Diener, 1993; Seidlitz, Wyer, \& Diener, 1997) and try to make the events in their lives more positive (Headey \& Wearing, 1989). Happiness has been found to be negatively associated with perceived stress (e.g., Schiffrin \& Nelson, 2010) and to play a role in protecting individuals from some of the negative consequences that stem from stress (Fredrickson \& Levenson, 1998; Fredrickson, Mancuso, Branigan, \& Tugade, 2000). It is important to note that we will be focusing on dispositional levels of happiness rather than its state-level features. In addition to influencing the way that individuals perceive stressful situations, the positive personality features of optimism, hope, and happiness have been found to be associated with how individuals feel about themselves such that individuals who report these features also tend to experience 
higher levels of self-esteem (e.g., Carvajal, Clair, Nash, \& Evans, 1998; Furnham \& Cheng, 2000).

The present study focused on the transition to higher education because this period creates considerable stress in the lives of new university students (D'Zurilla \& Sheedy, 1991; Towbes \& Cohen, 1996) and has been found to be associated with changes in the feelings of self-worth and psychological distress reported by students (e.g., Besser \& Zeigler-Hill, 2011; Cooke, Beewick, Barkham, Bradley, \& Audin, 2006; Zeigler-Hill \& Besser, 2011). First-year university students are forced to confront an array of stressors that are related to these new academic demands such as adapting to new learning environments and methods of instruction, receiving less individual support from instructors, competing for grades, trying to effectively manage more demands for their time, and engaging in the self-regulation that is necessary to develop their academic skills (e.g., Fram \& Bonvillian, 2001; Macan, Shahani, Dipboye, \& Phillips, 1990; Trueman \& Hartley, 1996). It is not uncommon for students to struggle during this transition period because they may not be fully prepared for higher education (e.g., they may lack appropriate study skills; Haggis \& Pouget, 2002) and may feel alienated from their social support networks (Walker, Matthew, \& Black, 2004). Given the stress associated with this transition, it is not surprising that first-year university students tend to report elevated levels of psychological distress compared with individuals in the general population (Busari, 2011; Cooke et al., 2006; Hall, Chipperfield, Perry, Ruthig, \& Goetz, 2006; Moffat, McConnachie, Ross, \& Morrisson, 2004).

\section{Overview and Predictions}

The positive personality characteristics of optimism, hope, and happiness are believed to play an important role in psychological adjustment to stressful life events and have been shown to be associated with fewer mood disturbances in response to a variety of stressors. However, relatively little is known about the capacity of these positive personality features to serve as sources of resilience for students as they deal with the transition to college. Studies that have focused on university students have concluded that the transition to life as a university student can be highly stressful for these individuals (e.g., Busari, 2011; Cooke, et al., 2006; D’Zurilla \& Sheedy, 1991; Hall et al., 2006; Moffat et al., 2004; Towbes \& Cohen, 1996). Although stress is an important aspect of personal and professional development, stress levels that are too high often have negative impacts on many aspects of the lives of students including their social, academic, and personal development (e.g., Fram \& Bonvillian, 2001; Haggis \& Pouget, 2002; Macan et al., 1990; Trueman \& Hartley, 1996; Walker et al., 2004) and on their self-worth (e.g., Besser \& Zeigler-Hill, 2011; Cooke et al., 2006; Zeigler-Hill \& Besser, 2011). As a result, the transitional period when students are beginning their training as university students was used as the context for examining the relationship between positive personality features and the levels of psychological distress, functional impairment, and self-esteem.

The purpose of the present study was to examine whether the positive personality features of optimism, hope, and happiness were associated with the levels of psychological distress (i.e., perceived stress, depressive symptoms, and anxiety), functional impairment, and self-esteem reported by new university students during the course of their first semester. We selected these outcomes because previous research has shown that each of these indicators is sensitive to stressful experiences (e.g., Nolen-Hoeksema \& Morrow, 1991). To accomplish our goal, we conducted a 
three-wave longitudinal study. The first wave included assessments of the positive personality features possessed by freshman university students during the first week of their first semester (before they had the chance to fully consider the potentially stressful academic demands that would be placed on them). The second wave of the study asked these students to report their responses to stress (i.e., psychological distress, functional impairment, and self-esteem) during the third week of the semester (after they had the opportunity to consider the potential stressful academic demands being placed on them). The third wave of the study asked students to report their responses to stress during the fifteenth week of the semester (during the stressful period of final examinations). We selected the final examination period as our "potential high stress period" because preparing for exams is a common source of stress among university students (e.g., Abouserie, 1994).

We expected that individuals who reported higher levels of the positive personality features at the beginning of the study would report lower levels of psychological distress, lower levels of functional impairment, and higher levels of self-esteem throughout the study (i.e., during the third and fifteenth weeks of the semester). That is, we expected the positive personality features to protect individuals from the adverse consequences of stress that accompanies the transition to college. The rationale for this prediction is that previous research has shown that optimism, hope, and happiness influence how individuals perceive stress and respond to other stressful situations (e.g., Cann \& Etzel, 2008; Cann et al., 2010). However, these previous studies were able to show that a composite measure of positive personality features was associated with perceived stress at the same point in time, whereas our study was intended to extend what is known about the connection between positive personality features and responses to stress using a longitudinal design. This methodological improvement is important because it will allow us to separate the reports of participants concerning their positive personality features from the reports of their responses to stress. This design will allow us to have greater confidence that positive personality features actually buffer individuals from the negative consequences of stress.

\section{Method}

\section{Participants and Procedure}

Participants were 260 undergraduate freshman university students (78 men and 182 women) at a university or a college in the southern region of Israel who were recruited to take part in a study concerning the transition to the university using an internet-based campus message board. Participants began the study during the first week of their first semester in college before they had received the syllabuses for their courses and had the opportunity to consider the academic demands being placed on them (Time-1) and 217 of them (83.5\%) were followed two weeks later when they had the chance to understand the demands being placed on them during the semester (Time-2) as well as during the final week of the semester as their final examinations were taking place (Time-3). We employed this design in order to separate the assessment of predictors (i.e., positive personality features) from the assessments of the potential mediators and/or outcomes (i.e., self-esteem and symptoms of psychological distress). The 43 participants who did not continue the study after Time-1 either dropped out of college or did not respond to our attempts to contact 
them for the follow-up sessions. Comparisons of participants who completed the study with those who failed to do so indicated that there were no significant differences between these groups based on the information that was available at Time-1 (i.e., age, gender, and positive personality features). The final 217 participants (74 men and 143 women) were young Jewish Israeli adults who had already served 2-4 years of mandatory service in the Israeli army. It is important to note that Israeli students are generally older than most Western students (i.e., the mean age of our participants was 23.62 years; range $20-30 ; S D=2.85$ ). Although Israeli college students are often somewhat older and more experienced than students in many other countries, they still tend to experience considerable stress during this transition period (e.g., Besser \& Zeigler-Hill, 2011; Shirom, 1986; ZeiglerHill \& Besser, 2011).

Participation in the study was voluntary and participants were not paid or compensated for their participation except for those who were enrolled in psychology courses and participated in return for partial fulfillment of a research participation requirement. Participants were asked to provide written informed consent after the procedures had been fully explained. The Time- 1 assessment consisted of a 25-minute laboratory session during which participants were asked to complete measures of positive personality characteristics (i.e., optimism, hope, and happiness). The Time- 2 and Time- 3 assessments consisted of a 45-minute laboratory session during which participants were asked to complete measures of self-esteem and symptoms of psychological distress (i.e., perceived stress, functional impairment, depression, and anxiety). All of the questionnaires used in the present study were administered in Hebrew after being translated from the original English versions using the back-translation method. Potential order effects were controlled at all three time-points by presenting the questionnaires in a randomized order. The participants were provided a written debriefing upon completion of the study.

\section{Measures}

\section{Time-1: Assessment of Positive Personality Characteristics}

Optimism. The Life Orientation Test-Revised (LOT-R; Scheier, Carver, \& Bridges, 1994) was used to capture optimism. The LOT-R consists of 10 items (six relevant items, e.g., "In uncertain times, I usually expect the best", and four irrelevant items, e.g., "It's easy for me to relax") and respondents provide a response for each item using scales that range from 0 (I disagree a lot) to 4 (I agree a lot). This questionnaire uses the average score of the six relevant items to capture dispositional optimism. The LOT-R has been found to possess adequate psychometric properties in past research (e.g., Scheier et al., 1994). This instrument was found to possess very good reliability for the present sample $(\alpha=.81)$.

Hope. The Trait Hope Scale (S. Snyder et al., 1991) was used to measure hope. This questionnaire consists of 12 items (eight relevant items, e.g., "There are lots of ways around any problem", and four irrelevant items, e.g., "I feel tired most of the time") and respondents provide a response for each item using scales that range from 1 (Definitely false) to 4 (Definitely true). This instrument uses the average score of the eight relevant items to capture dispositional hope. The Trait Hope Scale has been found to possess adequate psychometric properties in past research (e.g., S. Snyder et al., 1991) and the internal consistency of this measure was $\alpha=.85$ for the present study. 
Happiness. Happiness was assessed by the Subjective Happiness Scale (Lyubomirsky \& Lepper, 1999). This instrument is a 4-item measure of subjective, chronic happiness. The first item asks respondents about the extent to which they identify themselves as a happy person on a scale ranging from 1 (Not a very happy person) to 7 ( $A$ very happy person). The second item is a comparative assessment that requires respondents to describe themselves compared to their peers on a scale ranging from 1 (Less happy) to 7 (More happy). The third item asks respondents to rate the extent to which a description of a chronically happy person is accurate for them (i.e., "Some people are generally very happy. They enjoy life regardless of what is going on, getting the most out of everything. To what extent does this characterization describe you?') on a scale ranging from 1 (Not at all) to 7 ( $A$ great deal). The fourth item-which is reverse coded - asks respondents to rate the extent to which a description of a chronically unhappy person is accurate for them (i.e., "Some people are generally not very happy. Although they are not depressed, they never seem as happy as they might be. To what extent does this characterization describe you?') on a scale ranging from 1 (Not at all) to 7 ( $A$ great deal). The Subjective Happiness Scale has been found to possess adequate psychometric properties in past research (e.g., Lyubomirsky \& Lepper, 1999) and the internal consistency of this measure for the present study was $\alpha=.76$.

\section{Time-2 and Time-3: Assessment of Self-esteem, Psychological Distress Symptoms, and Functional Impairment}

Participants at Time-2 were asked to respond to the following measures of selfesteem and psychological distress based on their experiences during the transition to the university (e.g., experiences during the first couple of weeks). Participants at Time-3 were asked to respond to the items based on their experiences near the end of the semester (e.g., preparing for final examinations).

Self-esteem. The Rosenberg Self-Esteem Scale (Rosenberg, 1965) is a 10-item measure of global self-esteem (e.g., "On the whole, I am satisfied with myself"). Respondents were instructed to complete the instrument according to how they felt about themselves. Responses were made on scales ranging from 1 (Strongly disagree) to 5 (Strongly agree). This instrument is regarded as a well-validated and reliable measure of global self-regard (e.g., Blascovich \& Tomaka, 1991). The internal consistency of this measure for the present study was $\alpha=.84$ at Time- 2 and $\alpha=.88$ at Time-3.

Perceived stress. The Perceived Stress Scale (Cohen, Kamarck, \& Mermelstein, 1983; Cohen \& Williamson, 1988) is a self-report measure of stress. The scale includes 14 items that are designed to measure the degree to which individuals cognitively appraise their lives as unpredictable, uncontrollable, and overwhelming (e.g., "How often have you felt nervous and 'stressed'?"). Respondents were asked to rate how often they experienced a particular feeling or thought using scales that ranged from 0 (Never) to 4 (Very often). This instrument has been found to possess very good psychometric properties in past research (e.g., Cohen et al., 1983). The internal consistency of this measure for the present study was $\alpha=.81$ at Time-2 and $\alpha=.87$ at Time-3.

Depressive symptoms. The Center for Epidemiological Studies Depression Scale (CES-D; Radloff, 1977) is a 20-item scale designed to capture the severity of current depressive symptoms in the general population (e.g., "I felt sad"). The items assess elements of depression that include depressed mood, feelings of guilt and 
worthlessness, feelings of helplessness and hopelessness, psychomotor retardation, loss of appetite, and sleep disturbances (Radloff, 1977). This instrument has been extensively evaluated and has been shown to possess very strong psychometric properties (e.g., Eaton, Smith, Ybarra, Muntaner, \& Tien, 2004; Radloff, 1977). In the present sample, the estimate of internal consistency at Time-2 was $\alpha=.92$ and $\alpha=.93$ at Time- 3 .

Anxiety. The State Anxiety subscale of the State-Trait Anxiety Inventory (STAI; Spielberger, Gorsuch, \& Lushene, 1970) was used to capture anxiety. This measure consists of 20 different feelings and mood states (e.g., "I feel nervous"). Respondents were asked to rate the extent to which each item applied to them at that particular moment using scales that ranged from 1 (Not at all) to 4 (Very much so). This instrument has been found to possess adequate psychometric properties (e.g., Spielberger, Gorsuch, Lushene, Vagg, \& Jacobs, 1983). The internal consistency of this instrument for the present sample was .92 at Time-2 and .93 at Time-3.

Functional impairment. The Sheehan Disability Scale (Sheehan, Harnett-Sheehan, \& Raj, 1996) was used to assess the extent to which stress related to the transition to the university and the examination period had interfered with the functioning of respondents in three domains: work (e.g., "The stress associated with my transition to the university [or preparing for final examinations] has disrupted my work"), social life/leisure (e.g., "The stress associated with my transition to the university [or preparing for final examinations] has disrupted my social life/leisure"), and family life/home responsibilities (e.g., "The stress associated with my transition to the university [or preparing for final examinations] has disrupted my family life/ home responsibilities"). Participants rated their level of functional impairment in each domain using a visual analogue scale that ranged from 0 (None) to 10 (Very severe). Previous research has shown that this instrument possesses adequate psychometric properties (e.g., Mendlowicz \& Stein, 2000) and the estimate of internal consistency for the present study was .83 at Time- 2 and .84 at Time-3.

\section{Data Analytic Strategy}

Initial analyses (i.e., $t$-tests) were used to compare psychological distress and selfesteem at Time- 2 and Time- 3 in order to determine whether there was an increase in distress and a decrease in self-esteem during the course of the semester. These analyses were followed by analyses of competing measurement models as well as several structural models with different specifications. Cross-lagged panel correlation (CLPC) structural equation modeling (SEM; Hoyle \& Smith, 1994) was used to explore the associations between psychological distress symptoms (a latent variable for which perceived stress, depression, and anxiety served as indicators), functional impairment (a measured variable, i.e., non-latent), and self-esteem (a measured variable, i.e., non-latent) using an SEM strategy that assessed measurement errors for the dependent and independent variables (Hoyle \& Smith, 1994) with AMOS software (Version 18.0.0; Arbuckle, 2009) and the maximum-likelihood method. Several components of this model are noteworthy. First, it includes two time points - i.e., Time-2 (transition to the university) and Time-3 (examination period) and the effects of self-esteem, psychological distress symptoms, and functional impairment are estimated. This aspect of the model is referred to as a cross-lagged effect. Second, the model also includes the influence of psychological distress symptoms 
and functional impairment at Time-2 on psychological distress symptoms and functional impairment at the later time point. The same is true for self-esteem. These aspects of the model — called autoregressive effects - can be thought of as indicators of the temporal stability of the measures. Estimations of these parameters in the model control for the stability of the variables. Thus, any cross-lagged effects can be considered effects that add predictive power over and above that which can be simply obtained from the stability of the measures. Finally, note that psychological distress symptoms, functional impairment, and self-esteem are allowed to intercorrelate within each time point as represented by the curved, double-headed arrows. These aspects of the model are called synchronous correlations. Estimating these errors in the model allows for correlations between variances in psychological distress symptoms, functional impairment, and self-esteem that are not already explained by the influence of the variables from earlier time points (see Figure 1). Finally, we tested the direct effect of Time-1 positive personality characteristics (a latent variable for which optimism, hope, and happiness served as indicators) on the psychological distress symptoms latent construct and the functional impairment measured variable (i.e., non-latent) that were measured at Time-3 (examination period) utilizing SEM multivariate analysis (see Figure 2) and the mediating role of psychological distress symptoms, functional impairment, and self-esteem at Time-2 to examine the effect of positive personality characteristics (Time-1) on psychological distress symptoms, functional impairment, and self-esteem at Time-3 (see Figure 3). Using the criteria for testing mediation that was originally developed by Baron and Kenny (1986), we investigated the proposed mediation model in two stages. First, we analyzed the direct effects of positive personality characteristics (Time-1) on psychological distress symptoms, functional impairment, and self-esteem at Time-3 (controlling for their shared variance). Second, we specified the models of the direct and indirect effects of positive personality characteristics through psychological distress symptoms, functional impairment, and self-esteem at Time-2 (controlling for their shared variance).

In addition to the overall chi-square ( $\chi^{2}$ test of exact fit, the following fit indices were used to evaluate the proposed models: (a) the $\chi^{2} / d f$ ratio; (b) the root mean square error of approximation (RMSEA); (c) the comparative fit index $(C F I)$; and (d) the non-normed fit index (NNFI). A model in which $\chi^{2} / d f$ was $\leq 2, C F I$ and $N N F I$ were greater than 0.95 , and the $R M S E A$ index was between 0.00 and $0.08(\mathrm{Hu} \&$ Bentler, 1999) was deemed acceptable. These moderately stringent acceptance criteria clearly reject inadequate or poorly specified models, while accepting models for consideration that meet real-world criteria for reasonable fit and representation of the data (Kelloway, 1998).

We evaluated the proposed models by studying the sampling variability of estimates of the indirect effects using the bootstrap framework that has been proposed (e.g., Mallinckrodt, Abraham, Wei, \& Russell, 2006; Shrout \& Bolger, 2002). We implemented this procedure in the direct and mediational models by drawing 5,000 bootstrapping samples. We found that $100 \%$ of the bootstrap samples converged for all of the tested models. The two-sided $95 \%$ confidence intervals and the confidence intervals based on the bias-corrected bootstrap for the direct and indirect effects in these models were consistent with the conclusion that the direct and indirect effects are significantly different from zero ( $S E$ and twosided $95 \%$ CI values based on the bias-corrected bootstrap are reported in parentheses). These results suggest that this procedure led to a stable estimate of the distributions. 


\section{Results}

\section{Descriptive Statistics}

The means, standard deviations, and intercorrelations for the variables at each timepoint are presented in Table 1. Positive personality features (Time-1) had significant positive associations with self-esteem levels and negative associations with psychological distress symptoms and functional impairment at both Time-2 and Time-3. Self-esteem at Time-2 and Time-3 had significant negative associations with psychological distress and functional impairment at both Time-2 and Time-3. It is also important to note that significant positive associations emerged for the distress symptoms and functional impairment at both Time-2 and Time-3.

Changes in self-esteem and psychological distress from Time-2 to Time-3 were examined using dependent-samples $t$-tests. The self-esteem levels of participants did not differ between Time-2 and Time-3, $t(216)=1.48, n s ; 95 \%$ CI $[-0.01,0.08]$, but participants did report significant increases in psychological distress from Time-2 to Time-3 for perceived stress, $t(216)=4.13, p<.0001 ; 95 \%$ CI $[1.05,2.96], d=0.28,{ }^{1}$ depression, $t(216)=6.27, p<.0001 ; 95 \%$ CI [2.65, 5.07], $d=0.43$, and state anxiety, $t(216)=9.54, p<.0001 ; 95 \%$ CI [0.24, 0.36], $d=0.64$. Moreover, participants also reported significant increases in functional impairment from Time-2 to Time-3, $t(216)=6.69, p<.0001 ; 95 \%$ CI $[2.16,3.96], d=0.46$. These results show that participants experienced more distress and functional impairment at Time-3 than Time-2 even though their level of self-esteem did not differ.

\section{Multivariable Analyses}

\section{Analysis of the Measurement Model}

We analyzed the present data using a measurement model that delineated all of the associations between latent variables and observed variables. This measurement model included three latent variables: positive personality characteristics at Time-1, which were assessed by three indicators, and psychological distress at Time-2 and Time-3, which was assessed by three indicators at each point in time. Our model also included two observed variables: self-esteem and functional impairment (both of these observed variables were assessed at Time-2 and Time-3). This first measurement model specified was found to fit the observed data very well, $\chi^{2}(45)=58.11$, $p>.09, \chi^{2} / d f=1.29, N N F I=.97, C F I=.99, R M S E A=.03,90 \%$ CI [0.000, 0.06]. All the factor indicators, paths, and loading were substantial and statistically significant in the expected directions. Because depression and self-esteem are strongly correlated (Watson, Suls, \& Haig, 2002), one could assume that (low) self-esteem also could be modeled as an additional indicator of psychological distress. In order to explore the possibility that both assessments of psychological distress and (low) self-esteem may tap aspects of a single latent construct, we performed an additional CFA. This model was the same as the previous one except that we specified selfesteem at each time as an indicator of psychological distress (along with the original three indicators). This second measurement model did not fit the observed data, $\chi^{2}(53)=132.31, p<.0001, \chi^{2} / d f=2.50, N N F I=.92, C F I=.95, R M S E A=.08$, $90 \%$ CI [0.07, 0.10]. Finally, functional impairment and distress were strongly correlated (e.g., Phillips, 2009), which could lead to the assumption that functional impairment could be modeled as an additional indicator of psychological distress. In order to explore the possibility that both assessments of psychological distress and functional impairment may tap aspects of a single latent construct, we performed an 


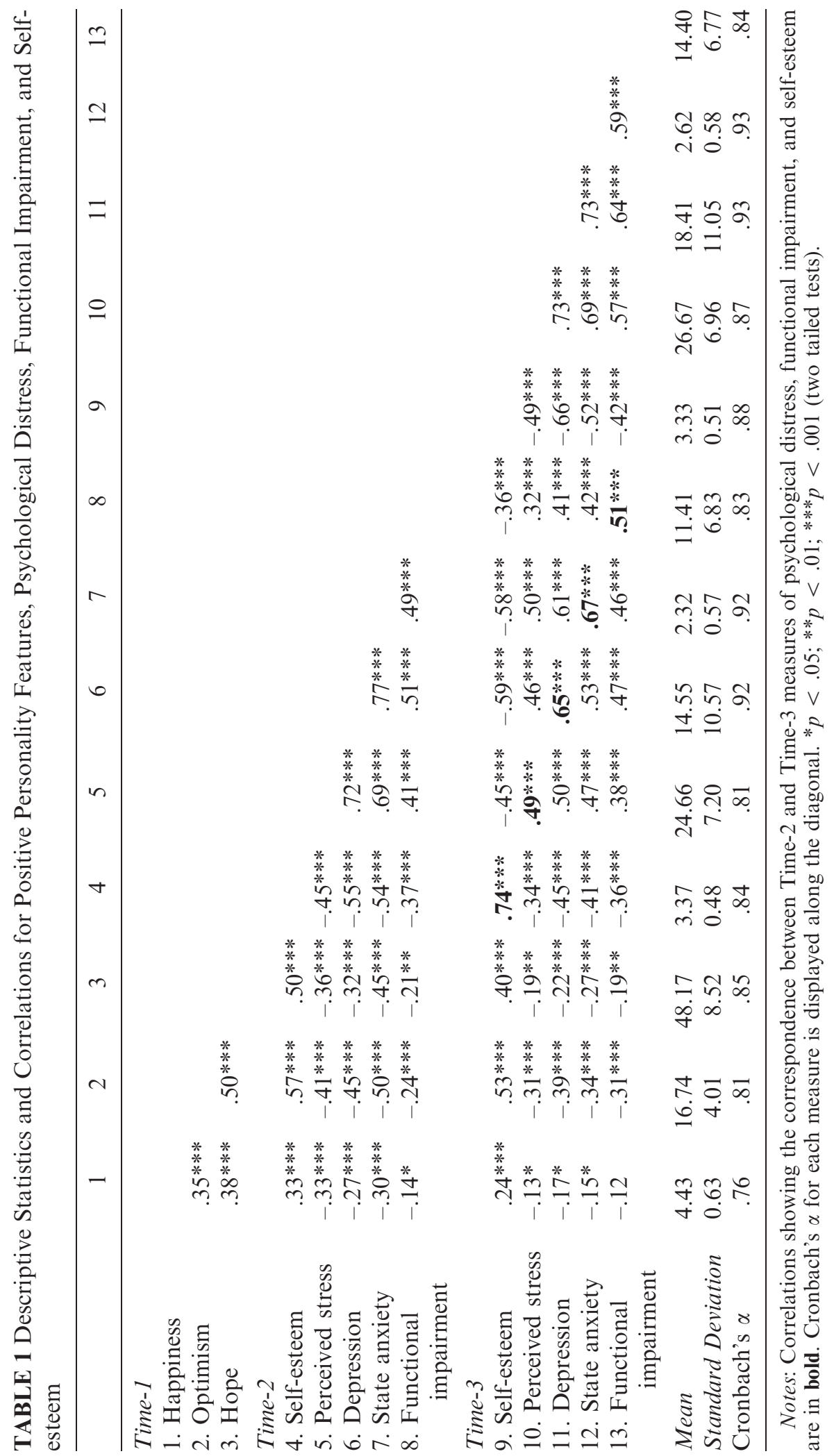


additional CFA. This model was the same as the previous one except that we specified three latent factors: positive personality characteristics (Time-1); psychological distress (at Time-2 and at Time-1) with functional impairment and self-esteem at each time point as indicators of psychological distress (along with the original three indicators). This third measurement model did not fit the observed data, $\chi^{2}(57)=135.77, p<.0001, \chi^{2} / d f=2.38, N N F I=.92$, CFI $=.95, R M S E A=.08$, $90 \%$ CI $[0.06,0.10]$. Results from the chi-square test of the differences between the first and the other two CFA models indicated that the first model significantly improved the fit to the data compared to the second model $\left(\Delta \chi^{2}=74.2, d f=8\right.$, $p<.0001)$ and the third model $\left(\Delta \chi^{2}=77.7, d f=12, p<.0001\right)$. We therefore proceeded to test structural models including the positive personality characteristics and psychological distress constructs and self-esteem and functional impairment variables as defined in the first CFA measurement model.

\section{Structural Models Specifications}

Cross-lagged model. The cross-lagged SEM model (see Figure 1) fit the observed data well, $\chi^{2}(21)=29.44, p>.11, \chi^{2} / d f=1.40, N N F I=.98, C F I=.99, R M S E A=$ $.04,90 \%$ CI $[0.000,0.07]$. This model showed non-significant associations between Time-2 self-esteem and Time-3 psychological distress symptoms $(\beta=-0.06$, $t=-0.93, n s)$ and functional impairment $(\beta=-0.05, t=-0.73, n s)$. Moreover, this model showed non-significant associations between Time-2 functional impairment and Time- 3 psychological distress symptoms $(\beta=0.06, t=0.98, n s)$ and selfesteem $(\beta=0.03, t=0.60, n s)$. In contrast, Time- 2 psychological distress symptoms had a noteworthy association with self-esteem and functional impairment at Time-3 as evidenced by the statistically significant cross-lagged coefficients $(\beta=-0.33$, $t=-4.70, p<.0001 ; S E=0.008,95 \%$ CI $[-0.05,-0.01], p<.0001$ and $\beta=0.31, \quad t=3.48, \quad p<.0001 ; \quad S E=0.11,95 \% \quad$ CI $[0.16,0.60], \quad p<.001$, respectively). These findings indicate that psychological distress symptoms during the transition to the university (Time-2) had significant direct associations with selfesteem and functional impairment at Time-3 (three months later) but that self-esteem and functional impairment levels at Time-2 did not directly predict levels of psychological distress at Time-3. Self-esteem and functional impairment at Time-2, however, predicted psychological distress at Time-3 indirectly through their associations with psychological distress symptoms at Time-2 (self-esteem: $\beta=-0.61, \quad t=-6.89, \quad p<.0001 ; \quad S E=0.28, \quad 95 \% \quad$ CI $\quad[-2.23, \quad-1.15]$, $p<.0001$; functional impairment: $\beta=0.56, t=6.51, p<.0001 ; S E=3.43,95 \%$ CI $[15.69,29.16], p<.0001)$, which was connected with psychological distress symptoms at Time-3 $(\beta=0.65, t=6.51, p<.0001 ; S E=0.09,95 \%$ CI [0.44, 0.63], $p<.0001)$. Self-esteem at Time- 2 also predicted psychological distress symptoms at Time-3 indirectly through its association with self-esteem at Time-3 $(\beta=0.55$, $t=9.82, p<.0001 ; S E=0.08,95 \%$ CI [0.42, 0.73], $p<.001)$, which was associated with psychological distress symptoms at the same point in time $(\beta=-0.42, \quad t=-4.56, \quad p<.0001 ; \quad S E=0.12, \quad 95 \% \quad$ CI $\quad[-0.79, \quad-0.32]$, $p<.0001)$. Functional impairment at Time-2 also predicted psychological distress symptoms at Time-3 indirectly through its association with functional impairment at Time-3 ( $\beta=0.32, t=4.59, p<.0001 ; S E=0.07,95 \%$ CI $[0.16,0.45], p<.0001)$, which was associated with psychological distress symptoms at the same point in time $(\beta=0.56, t=6.14, p<.0001 ; S E=2.67,95 \%$ CI $[7.54,18.54], p<.0001)$. 


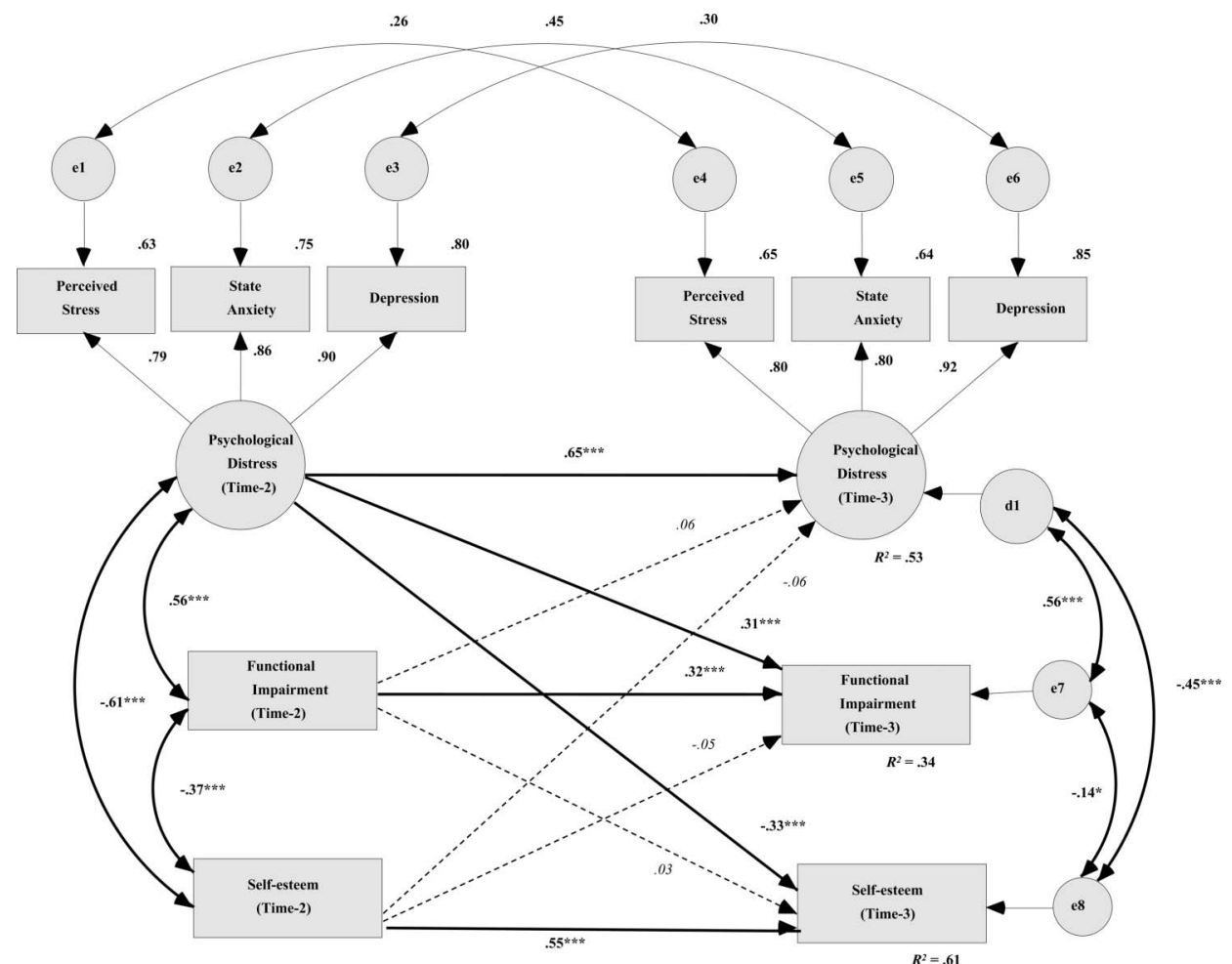

FIGURE 1 The crossed-lagged effects of psychological distress symptoms, functional impairment, and self-esteem at the transition period (Time-2) and the examination period (Time-3). Notes: Rectangles indicate measured variables and large circles represent latent constructs. Small circles reflect residuals (e) or disturbances (d); bold numbers above or near endogenous variables represent the amount of variance explained $\left(R^{2}\right)$. Bidirectional arrows depict correlations and unidirectional arrows depict hypothesized directional or "causal" links. Standardized maximum likelihood parameters are used. Bold estimates are statistically significant. The dotted paths indicate non-significant, "causal" links/associations. This model controlled for the autocorrelations among same measures errors of the indicators of psychological distress at Time- 2 and 3 (within subject repeated measures). ${ }^{*} p<.05$; ${ }^{* * *} p<.001$ (two tailed).

Finally, self-esteem and functional impairment were significantly associated at both Time-2 $(\beta=-0.37, t=-5.07, p<.0001 ; S E=0.25,95 \%$ CI $[-1.69,-0.73]$, $p<.0001)$ and Time-3 $(\beta=-0.14, t=-2.00, p<.046 ; S E=0.13,95 \%$ CI $[-0.52,0.01], p<.05)$.

Direct-effects model. The direct effect model (see Figure 2) fit the observed data well, $\chi^{2}(16)=26.06, p>.05, \chi^{2} / d f=1.63, N N F I=.97, C F I=.99, R M S E A=.05$, $90 \%$ CI $[0.000,0.08]$. This model showed that positive personality characteristics (Time-1) had significant associations with Time-3 psychological distress symptoms $(\beta=-0.48, \quad t=-5.52, \quad p<.0001 ; \quad S E=0.17, \quad 95 \% \quad$ CI $[-1.20, \quad-0.54]$, $p<.0001)$, self-esteem $(\beta=0.64, t=7.69, p<.0001 ; S E=0.01,95 \%$ CI $[0.08$, $0.13], p<.001)$, and functional impairment $(\beta=-0.35, t=-4.44, p<.0001$; 


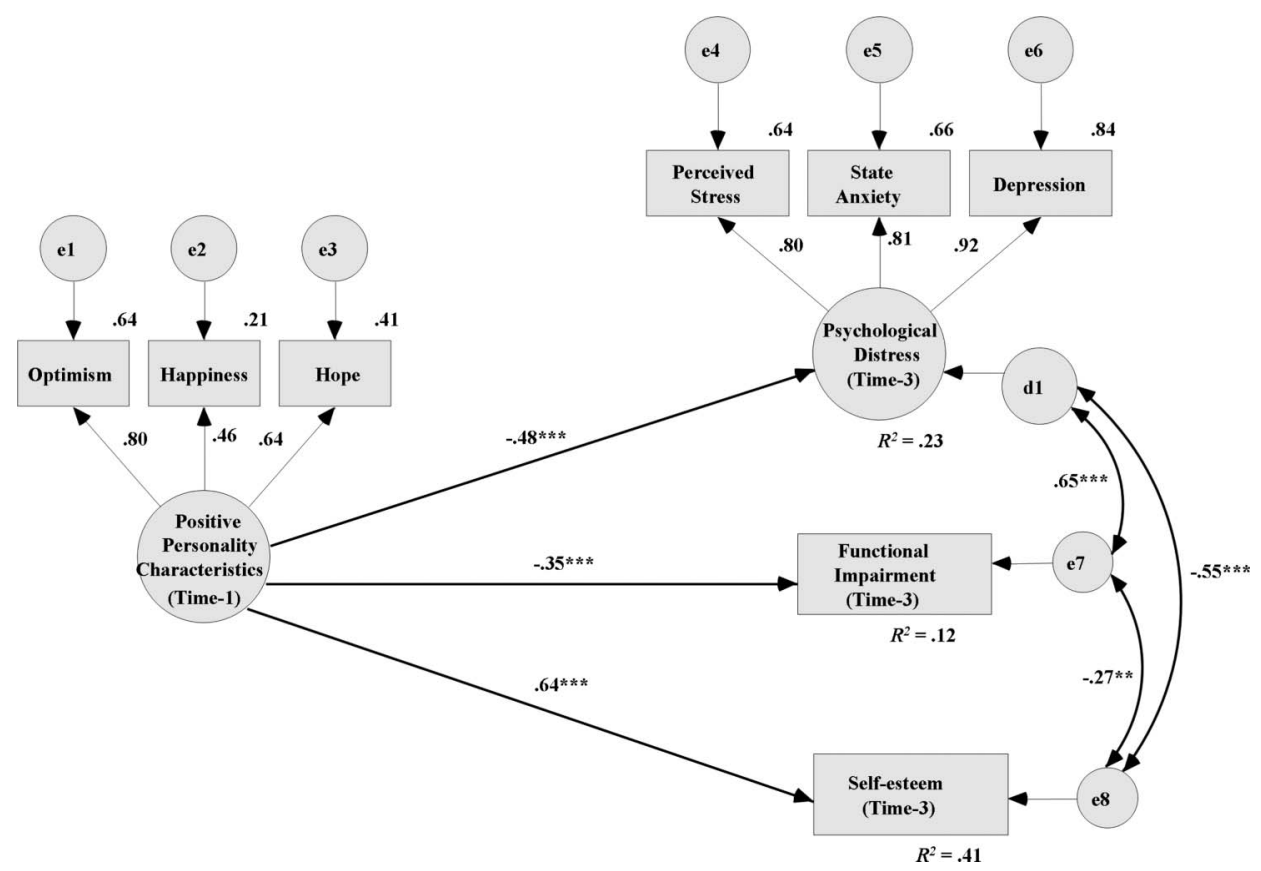

FIGURE 2 The association between positive personality characteristics (Time-1) and psychological distress symptoms and functional impairment at examination period (Time-3). Notes: Rectangles indicate measured variables and large circles represent latent constructs. Small circles reflect residuals (e) or disturbances (d); bold numbers above or near endogenous variables represent the amount of variance explained $\left(R^{2}\right)$. Bidirectional arrows depict correlations and unidirectional arrows depict hypothesized directional or "causal" links. Standardized maximum likelihood parameters are used. Bold estimates are statistically significant. The dotted paths indicate nonsignificant, "causal" links/associations. $* * p<.01 ; * * *<.001$ (two tailed).

$S E=0.18,95 \%$ CI $[-1.10,-0.39], p<.0001)$. These findings indicate that the positive personality characteristics possessed by students at the beginning of their transition to the university (Time-1) significantly predicted the levels of psychological distress, functional impairment, and self-esteem these students reported three months later during their final examination period. These effects were not altered when we controlled for demographic factors (i.e., gender and age) and the associations of these demographic factors with predictors and outcomes. The results of this model emphasize the importance of positive personality features as factors that exert a significant influence on psychological well-being and suggest that individuals who are predisposed to experience optimism, hope, and happiness are likely to enjoy a number of benefits including less susceptibility to distress, lower levels of functional impairment, and higher levels of self-esteem.

Mediation model. The mediation model (see Figure 3) fit the observed data very well, $\chi^{2}(45)=58.11, p>.09, \chi^{2} / d f=1.29, N N F I=.97, C F I=.99, R M S E A=.03$, $90 \%$ CI $[0.000,0.06]$. Positive personality features had a significant negative association with psychological distress symptoms at Time-2 $(\beta=-0.69, t=-7.39$, $p<.0001 ; S E=0.20,95 \%$ CI $[-1.75,-0.97], p<.0001)$, which, in turn, had associations with psychological distress symptoms at Time-3 $(\beta=0.70, t=6.01$, 


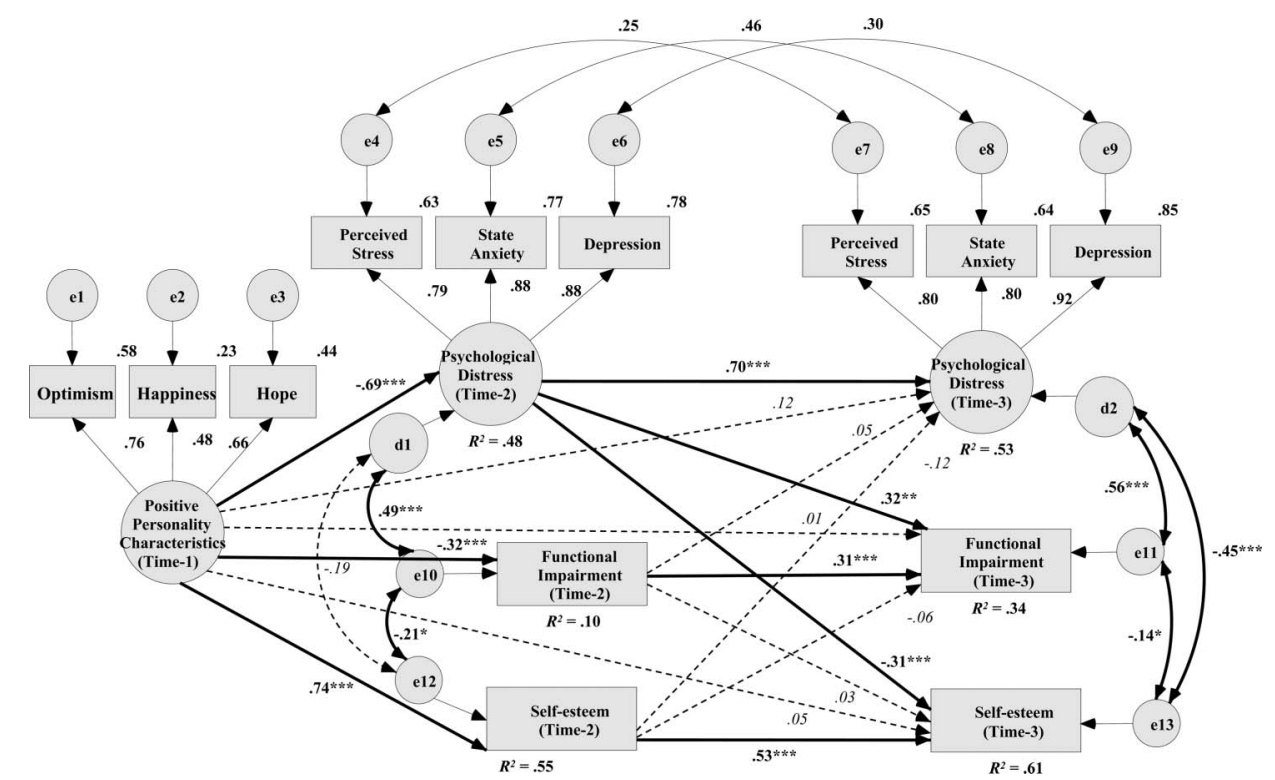

FIGURE 3 Psychological distress symptoms, functional impairment and self-esteem at the transition period (Time-2) mediate the effect of positive personality features (Time-1) on psychological distress symptoms, functional impairment, and selfesteem at examination period (Time-3). Notes: Rectangles indicate measured variables and large circles represent latent constructs. Small circles reflect residuals (e) or disturbances (d); bold numbers above or near endogenous variables represent the amount of variance explained $\left(R^{2}\right)$. Bidirectional arrows depict correlations and unidirectional arrows depict hypothesized directional or "causal" links. Standardized maximum likelihood parameters are used. Bold estimates are statistically significant. The dotted paths indicate non-significant, "causal" links/associations. This model controlled for the autocorrelations among same measures errors of the indicators of psychological distress at Time-2 and 3 (within subject repeated measures). ${ }^{*} p<.05 ; * *<.01 ; * * *<.001$ (two tailed).

$p<.0001 ; S E=0.13,95 \%$ CI [0.45, 0.97], $p<.0001)$, functional impairment at Time-3 ( $\beta=0.32, t=2.77, p<.006 ; S E=0.16,95 \%$ CI $[0.07,0.68], p<.01)$, and self-esteem at Time-3 $(\beta=-0.31, t=-3.50, p<.0001 ; S E=0.01,95 \% \mathrm{CI}$ $[-0.05,-0.01], p<.01)$. Positive personality characteristics were also significantly associated with self-esteem at Time-2 $(\beta=0.74, t=8.90, p<.0001 ; S E=0.014$, $95 \%$ CI $[0.09,0.15], p<.0001)$, which, in turn, was associated with self-esteem at Time-3 ( $\beta=0.53, t=6.76, p<.0001 ; S E=0.10,95 \%$ CI [0.37, 0.75], $p<.0001)$. Finally, positive personality characteristics were also significantly associated with functional impairment at Time-2 $(\beta=-0.32, t=-0.89, p<.0001 ; S E=0.20$, $95 \%$ CI $[-1.11,-0.32], p<.001)$, which, in turn, was associated with functional impairment at Time-3 $(\beta=0.31, t=4.38, p<.0001 ; S E=0.08,95 \%$ CI $[0.15$, $0.46], p<.001)$. Taken together, these results suggest that the associations that positive personality features had with Time-3 psychological distress, functional impairment, and self-esteem (Figure 2) were mediated by Time-2 levels of psychological distress, functional impairment, and self-esteem (Figure 3). This mediation is indicated by the fact that the direct paths from positive personality features at Time-1 to psychological distress, functional impairment, and self-esteem 
at Time- 3 failed to reach conventional levels of significance after the introduction of Time-2 psychological distress, functional impairment, and self-esteem as potential mediators $(\beta=0.12, t=0.83, n s ; \beta=0.01, t=0.09, n s$; and $\beta=0.05, t=0.41, n s$, respectively). Thus, the significant direct effects of Time-1 positive personality features on Time-3 psychological distress, functional impairment, and self-esteem are significantly mediated by Time- 2 psychological distress $(S E=0.29,95 \%$ CI $[-1.76$, $-0.65], p<.0001)$, functional impairment $(S E=0.32,95 \%$ CI [0.07, 0.15], $p<.0001)$, and self-esteem $(S E=0.19,95 \%$ CI $[0.07,0.15], p<.001)$. These mediational effects were not altered when we controlled for demographic features.

\section{Discussion}

The present study is one of the first investigations of the protective effects of positive personality features on psychological distress, functional impairment, and self-esteem for individuals making the transition to life as a college student. There was a significant increase in distress symptoms and functional impairment during the course of the semester and positive personality features were associated with the level of distress and functional impairment reported by participants. However, it is important to note that positive personality features were most important for predicting distress, functional impairment, and self-esteem at the beginning of the semester rather than the end of the semester. That is, the connections between positive personality features and outcomes at the end of the semester were mediated by the assessment of these outcomes near the beginning of the semester. These results suggest the intriguing possibility that positive personality features may demonstrate their strongest protective properties early in the process of a prolonged period of stress (e.g., near the beginning of the semester for new students). However, it is important to note that the temporal proximity of the Time- 1 and Time- 2 measures (approximately two weeks apart) may partially explain the strength of their association compared with the Time-3 measures, which took place approximately three months later. Also, controlling for the measures of psychological distress, functional impairment, and self-esteem at Time-2 may have attenuated the associations that positive personality features had with these outcomes at Time- 3 .

The current findings regarding the association between positive personality qualities and distress extend previously reported cross-sectional (Cann \& Etzel, 2008) and longitudinal findings (Cann et al., 2010). These previous studies were able to show that a composite measure of positive personality features was associated with perceived stress at the same point in time. Our study extends these previous findings by showing that positive personality features are associated with later reports of responses to stress within a model that incorporates longitudinal data that allows for the separation of the assessments of positive personality features from those of psychological distress, functional impairment, and self-esteem.

The associations between positive personality features and responses to stress at Time- 3 were found to be fully mediated by the responses to stress that individuals reported at Time- 2 . These findings point to an important mechanism regarding the significance of positive personality features in protecting individuals from distress outcomes during an ongoing period of stress. This association between positive personality features and the outcomes of stress appear to be especially important during the initial transition period. This suggests that positive personality features may exert their greatest protective influences during the earliest stages of relatively extended stressogenic life transition periods. The resilience displayed by individuals with high 
levels of positive personality features is likely due, at least in part, to their ability to see the world through a more positive lens than those who lack these features.

The results of the current study suggest that psychological distress at Time- 2 may have led to greater distress, more functional impairment, and lower self-esteem at Time-3. This pattern of results is consistent with the "scar model" of self-esteem, which suggests that the commonly observed association between self-esteem and psychological distress is due to low self-esteem sometimes being an outcome of psychological distress rather than a cause (e.g., Coyne, Gallo, Klinkman, \& Calarco, 1998; Coyne \& Whiffen, 1995). The underlying rationale for this model is that psychological distress persistently deteriorates personal resources, which leave "scars" on the self-concept of the individual that progressively chip away at selfesteem over time. Our results are similar to those of previous studies supporting the scar hypothesis such that psychological distress was a potent predictor of later selfesteem levels (e.g., Shahar \& Davidson, 2003; Shahar \& Henrich, 2010). The emerging pattern appears to suggest that the effects of distress on self-esteem may be particularly salient during stressful periods that occur relatively early in life. This is particularly noteworthy for those working with college students given that distress symptoms are so prevalent during this key transitional period as students adjust to the new demands that are placed on them during their freshman year (e.g., Busari, 2011; Cooke et al., 2006; D’Zurilla \& Sheedy, 1991; Hall et al., 2006; Moffat et al., 2004; Towbes \& Cohen, 1996). Thus, stressors that are related to life-transitionsand the resulting distress - appear to have the capacity to erode self-esteem. However, it is important to note that our results are at least somewhat inconsistent with the results of a recent meta-analysis by Sowislo and Orth (in press), which found that self-esteem predicted subsequent levels of depression and anxiety. This discrepancy in results may be due to the fact that our first assessment of self-esteem took place at Time-2, which was a period of transitional stress. We may have obtained results that were more consistent with those observed by Sowislo and Orth if we had also assessed self-esteem at Time-1 (i.e., prior to the onset of any sort of transitional stress).

\section{Clinical Implications}

The results of the present study suggest that universities may want to pay particular attention to the distress of students during the initial transition period. This may be a time when interventions may be particularly helpful for university students. Students who lack the protective resources provided by positive personality features may have an especially strong need for these sorts of interventions. For example, universities may want to make students aware of the various resources that are available to them (e.g., counseling services, workshops). Further, universities may find it beneficial to target some of their resources toward helping transitional students maintain or develop positive personality features (e.g., optimism, hope, happiness) because these characteristics may be especially beneficial for first-year college students as they struggle to deal with an array of stressful situations during their adjustment to life as a college student.

\section{Limitations and Directions for Future Research}

Although the present study had a number of strengths (e.g., large sample, multiple measures of positive personality features and psychological distress, repeated 
assessment of psychological distress and self-esteem), it also had a number of limitations. The first limitation was our reliance on only two waves of measurement for psychological distress, functional impairment, and self-esteem. The fact that we did not include measures of distress, functional impairment, and self-esteem at Time1 makes it impossible to examine their connections throughout the entire course of the semester and prevents us from controlling for the pre-existing levels of these factors that the participants possessed prior to the onset of stress. As a result, our design is similar to what Cole and Maxwell (2003) refer to as a half-longitudinal design. Future studies interested in examining the protective properties of positive personality features should include outcome measures at all time-points. Moreover, future researchers may want to consider measuring the positive personality features at all three time points, which would allow them to rule out the possibility of a potential "scar" effect on these personality features as well using a "full" longitudinal crossed lagged design.

The second limitation of the present research is that we only included a single measure of self-esteem. Although the Rosenberg Self-Esteem Scale is the most commonly used measure of self-esteem, there are other measures that may have provided a more nuanced view of the construct. For example, future researchers may want to consider including domain-specific measures of self-esteem to complement what may be found with a global measure such as the Rosenberg Self-Esteem Scale. It may be especially informative to include a measure of selfesteem that assesses academic self-esteem in order to determine whether positive personality features offer some protection against the detrimental consequences of stress for this domain of self-esteem. Also, the inclusion of state self-esteem measures may be more sensitive to the changes in feelings of self-worth brought on by stressful experiences. The fact that we did not include a measure of state selfesteem may explain why the change in self-esteem was not larger across the semester. The third limitation is that we relied exclusively on self-report measures. There are a number of reporting biases (e.g., socially desirable responding) that may have influenced our results. Future researchers may want to consider including some non-self-report measures to reduce shared method variance. The fourth limitation is that the present study is limited in terms of its ability to determine causal relations between variables. Despite this limitation, the present study asked participants to report on their experiences during a stressful period of life transition in order to investigate an important phenomenon that is likely to have significant ecological validity. One possible direction that should be considered for future research is the possibility that distress erodes positive personality features in the same way that it appears to erode self-esteem. This hypothesis requires the repeated assessment of positive personality features along with distress in order to examine their crossed-lagged associations. This would allow future researchers to determine whether high levels of distress exert the same corrosive influence on these positive personality features as it does on self-esteem. Despite its limitations our study shed light on important potential mechanisms that link sources of resilience and vulnerability for students as they deal with the transition to life as a college student.

\section{Note}

1. Cohen's $d$ has been corrected for dependence between means using Equation 8 from Morris and DeShon (2002). 


\section{References}

Abouserie, R. (1994). Sources and levels of stress in relation of control and self-esteem in university students. Educational Psychology, 14, 232-330.

Affleck, G., \& Tennen, H. (1996). Construing benefits from adversity: Adaptational significance and dispositional underpinnings. Journal of Personality, 64, 899-922.

Arbuckle, J. L. (2009). AMOS: A structural equation modeling program. Chicago, IL: Small Waters.

Baron, R. M., \& Kenny, D. A. (1986). The moderator-mediator variable distinction in social psychological research: Conceptual, strategic, and statistical considerations. Journal of Personality and Social Psychology, 51, 1173-1182.

Besser, A., \& Zeigler-Hill, V. (2011). Pathological forms of narcissism and perceived stress during the transition to the university: The mediating role of humor styles. International Journal of Stress Management, 18, 197-221.

Blascovich, J., \& Tomaka, J. (1991). Measures of self-esteem. In J. Robinson, P. Shaver, \& L. Wrightsman (Eds.), Measures of personality and social psychological attitudes (pp. 161194). New York, NY: Academic Press.

Busari, A. O. (2011). Validation of Student Academic Stress Scale (SASS). European Journal of Social Sciences, 21, 94-105.

Cann, A., \& Etzel, K. C. (2008). Remembering and anticipating stressors: Positive personality mediates the relationship with sense of humor. Humor, 21, 157-178.

Cann, A., Stilwell, K., \& Taku, K. (2010). Humor styles, positive personality and health. Europe's Journal of Psychology, 3, 213-235.

Carvajal, S. C., Clair, S. D., Nash, S. G., \& Evans, R. I. (1998). Relating optimism, hope and self-esteem to social influences in deterring substance use in adolescents. Journal of Social and Clinical Psychology, 17, 443-465.

Carver, C. S., \& Scheier, M. F. (2001). Optimism, pessimism, and self-regulation. In E. C. Chang (Ed.), Optimism and pessimism: Implications for theory, research, and practice (pp. 31-51). Washington, DC: American Psychological Association.

Carver, C. S., Scheier, M. F., \& Miller, C. J. (2009). Optimism. In S. J. Lopez \& C. R. Snyder (Eds.), Oxford handbook of positive psychology (pp. 303-312). New York, NY: Oxford University Press.

Carver, C. S., Scheier, M. F., \& Segerstrom, S. C. (2010). Optimism. Clinical Psychology Review, 30, 879-889.

Carver, C. S., Scheier, M. F., \& Weintraub, J. K. (1989). Assessing coping strategies: A theoretically based approach. Journal of Personality and Social Psychology, 56, 267-283.

Cohen, S., Kamarck, T., \& Mermelstein, R. (1983). A global measure of perceived stress. Journal of Health and Social Behavior, 24, 386-396.

Cohen, S., \& Williamson, G. (1988). Perceived stress in a probability sample of the United States. In S. Spacapan \& S. Oskamp (Eds.), The social psychology of health (pp. 31-67). Newbury Park, CA: Sage.

Cole, D. A., \& Maxwell, S. E. (2003). Testing mediational models with longitudinal data: Questions and tips in the use of structural equation modeling. Journal of Abnormal Psychology, 112, 558-577.

Cooke, R., Beewick, B. M., Barkham, M., Bradley, M., \& Audin, K. (2006). Measuring, monitoring and managing the psychological well-being of first year university students. British Journal of Guidance \& Counselling, 34, 505-517.

Coyne, J. C., Gallo, S. M., Klinkman, M. S., \& Calarco, M. M. (1998). Effects of recent and past major depression and distress on self-concept and coping. Journal of Abnormal Psychology, 107, 86-96.

Coyne, J. C., \& Whiffen, V. E. (1995). Issues in personality as diathesis for depression: The case of sociotropy/dependency and autonomy/self-criticism. Psychological Bulletin, 118, 358-378.

D'Zurilla, T. J., \& Sheedy, C. F. (1991). Relation between social problem-solving ability and subsequent level of psychological stress in college students. Journal of Personality and Social Psychology, 61, 841-846. 
Diener, E. (2000). Subjective well-being: The science of happiness and a proposal for a national index. The American Psychologist, 55, 34- 43.

Eaton, W. W., Smith, C., Ybarra, M., Muntaner, C., \& Tien, A. (2004). Center for Epidemiologic Studies Depression Scale: Review and revision (CESD and CESD-R). In M. E. Maruish (Ed.), The use of psychological testing for treatment planning and outcomes assessment. Vol. 3: Instruments for adults (3rd ed., pp. 363-377). Mahwah, NJ: Lawrence Erlbaum Associates, Inc.

Folkman, S. (2010). Stress, coping, and hope. Psychooncology, 19, 901-908.

Fram, E. H., \& Bonvillian, G. (2001). Employees as part-time students: Is stress threatening the quality of their business education? Advanced Management Journal, 66, 30-35.

Fredrickson, B. L., \& Levenson, R. W. (1998). Positive emotions speed recovery from the cardiovascular sequelae of negative emotions. Cognition and Emotion, 12, 191-220.

Fredrickson, B. L., Mancuso, R. A., Branigan, C., \& Tugade, M. M. (2000). The undoing effect of positive emotion. Motivation and Emotion, 24, 237-258.

Furnham, A., \& Cheng, H. (2000). Perceived parental behaviour, self-esteem and happiness. Social Psychiatry and Psychiatric Epidemiology, 35, 463-470.

Haggis, T., \& Pouget, M. (2002). Trying to be motivated: Perspectives on learning from younger students accessing higher education. Teaching in Higher Education, 7, 323-336.

Hall, N. C., Chipperfield, J. G., Perry, R. P., Ruthig, J. C., \& Goetz, T. (2006). Primary and secondary control in academic development: Gender-specific implications for stress and health in college students. Anxiety, Stress, and Coping, 19, 189-210.

Headey, B., \& Wearing, A. (1989). Personality, life events, and subjective well-being: Toward a dynamic equilibrium model. Journal of Personality and Social Psychology, 57, 731-739.

Hoyle, R. H., \& Smith, G. T. (1994). Formulating clinical research hypotheses as structural equation models: A conceptual overview. Journal of Consulting and Clinical Psychology, 62, 429-440.

Hu, L., \& Bentler, P. M. (1999). Cutoff criteria for fit indexes in covariance structure analysis: Conventional criteria versus new alternatives. Structural Equation Modeling, 6, 1-55.

Kelloway, E. K. (1998). Using LISREL for structural equation modeling: A researcher's guide. Newbury Park, CA: Sage.

Lazarus, R. S., \& Folkman, S. (1984). Stress, appraisal, and coping. New York, NY: Springer.

Lyubomirsky, S., \& Lepper, H. S. (1999). A measure of subjective happiness: Preliminary reliability and construct validation. Social Indicators Research, 46, 137-155.

Macan, T. H., Shahani, C., Dipboye, R. L., \& Phillips, A. P. (1990). College students' time management: Correlations with academic performance and stress. Journal of Educational Psychology, 82, 760-768.

Malach-Pines, A., \& Keinan, G. (2007). Stress and burnout in Israeli police officers during a Palestinian uprising (Intifada). International Journal of Stress Management, 14, 160-174.

Mallinckrodt, B., Abraham, T. W., Wei, M., \& Russell, D. W. (2006). Advance in testing statistical significance of mediation effects. Journal of Counseling Psychology, 53, 372-378.

McCullough, M. E., \& Snyder, C. R. (2000). Classical sources of human strength: Revisiting an old home and building a new one. Journal of Social and Clinical Psychology, 19, 1-10.

Mendlowicz, M. V., \& Stein, M. B. (2000). Quality of life in individuals with anxiety disorders. American Journal of Psychiatry, 157, 669-682.

Moffat, K. J., McConnachie, A., Ross, S., \& Morrisson, J. M. (2004). First year medical school stress and coping in problem-based learning medical curriculum. Medical Education, 38, 482-491.

Morris, S. B., \& DeShon, R. P. (2002). Combining effect size estimates in meta-analysis with repeated measures and independent-groups designs. Psychological Methods, 7, 105-125.

Nolen-Hoeksema, S., \& Morrow, J. (1991). A prospective study of depression and posttraumatic stress symptoms after a natural disaster: The 1989 Loma Prieta earthquake. Journal of Personality and Social Psychology, 61, 115-121.

Park, N., Peterson, C., \& Seligman, M. E. P. (2004). Strengths of character and well-being. Journal of Social and Clinical Psychology, 23, 603-619. 
Phillips, M. R. (2009). Is distress a symptom of mental disorders, a marker of impairment, both or neither? World Psychiatry, 8, 91-92.

Radloff, L. S. (1977). The CES-D scale: A self-report depression scale for research in the general population. Applied Psychological Measurement, 1, 385-401.

Rosenberg, M. (1965). Society and the adolescent self-image. Princeton, NJ: Princeton University Press.

Scheier, M. F., \& Carver, C. S. (1985). Optimism, coping, and health: Assessment and implications for generalized outcome expectancies. Health Psychology, 4, 219-247.

Scheier, M. F., Carver, C. S., \& Bridges, M.W. (1994). Distinguishing optimism from neuroticism (and trait anxiety, self-mastery, and self-esteem): A reevaluation of the Life Orientation Test. Journal of Personality and Social Psychology, 67, 1063-1078.

Schiffrin, H. H. \& Nelson, S. K. (2010). Stressed and happy? Investigation of the relationship between happiness and perceived stress. Journal of Happiness Studies, 11, 33-39.

Seidlitz, L., \& Diener, E. (1993). Memory for positive versus negative life events: Theories for the differences between happy and unhappy persons. Journal of Personality and Social Psychology, 64, 654-664.

Seidlitz, L., Wyer, R. S., \& Diener, E. (1997). Cognitive correlates of subjective well-being: The processing of valenced life events by happy and unhappy persons. Journal of Research in Personality, 31, 240-256.

Seligman, M. E. P. (2002). Authentic happiness. New York, NY: Free Press.

Seligman, M. E. P., \& Csikszentmihalyi, M. (2000). Positive psychology: An introduction. American Psychologist, 55, 5-14.

Shahar, G., \& Davidson, L. (2003). Depressive symptoms erode self-esteem in severe mental illness: A three-wave, cross-lagged study. Journal of Consulting \& Clinical Psychology, 71, 890-900.

Shahar, G., \& Henrich, C. C. (2010). Do depressive symptoms erode self-esteem in early adolescence? Self and Identity, 9, 403-415.

Sheehan, D. V., Harnett-Sheehan, K., \& Raj, B. A. (1996). The measurement of psychopharmacology. International Clinical Psychopharmacology, 11, 89-95.

Shirom, A. (1986). On the cross-environment generality of the relational view of stress. Journal of Environmental Psychology, 6, 121-134.

Shrout, P. E., \& Bolger, N. (2002). Mediation in experimental and nonexperimental studies: New procedures and recommendations. Psychological Methods, 7, 422-445.

Snyder, C. R. (2000). The past and possible futures of hope. Journal of Social and Clinical Psychology, 19, 11-28.

Snyder, C. R., Rand, K. L., \& Sigmon, D. R. (2002). Hope theory. In C. R. Snyder \& S. J. Lopez (Eds.), Handbook of positive psychology (pp. 257-276). New York, NY: Oxford University Press.

Snyder, S. T., Harris, C., Anderson, J. R., Holleran, S. A., Irving, L. M., \& Sigmon, S. T. (1991). The will and the ways: Development and validation of an individual-differences measure of hope. Journal of Personality and Social Psychology, 60, 570-585.

Sowislo, J. F., \& Orth, U. (in press). Does low self-esteem predict depression and anxiety? A meta-analysis of longitudinal studies. Psychological Bulletin.

Spielberger, C. D., Gorsuch, R. L., \& Lushene, R. E. (1970). Manual for the State-Trait Anxiety Inventory. Palo Alto, CA: Consulting Psychologists Press.

Spielberger, C. D., Gorsuch, R. L., Lushene, P. R., Vagg, P. R., \& Jacobs, A. G. (1983). Manual for the State-Trait Anxiety Inventory. Palo Alto, CA: Consulting Psychologists Press.

Towbes, L. C., \& Cohen, L. H. (1996). Chronic stress in the lives of college students: Scale development and prospective prediction of distress. Journal of Youth and Adolescence, 25, 199-217.

Trueman, M., \& Hartley, J. (1996). A comparison between the time management skills and academic performance of mature and traditional entry university students. Higher Education, 32, 199-215. 
Vermunt, R., \& Steensma, H. (2005). How can justice be used to manage stress in organizations? In J. Greenberg \& J. A. Colquitt (Eds.), Handbook of organizational justice (pp. 383-410). Mahwah, NJ: Lawrence Erlbaum Associates, Inc.

Vinokur, A., \& Selzer, M. L. (1975). Desirable versus undesirable life events: Their relationship to stress and mental distress. Journal of Personality and Social Psychology, 32, 329-337.

Walker, L., Matthew, B., \& Black, F. (2004). Widening access and student non-completion: An inevitable link? Evaluating the effects of the Top-Up Programme on student completion. International Journal of Lifelong Education, 23, 43-59.

Watson, D., Suls, J., \& Haig, J. (2002). Global self-esteem in relation to structural models of personality and affectivity. Journal of Personality and Social Psychology, 83, 185-197.

Wheaton, B. (1990). Life transitions, role histories, and mental health. American Sociological Review, 55, 209-223.

Zeigler-Hill, V., \& Besser, A. (2011). Humor style mediates the association between pathological narcissism and self-esteem. Personality and Individual Differences, 50, 1196-1201. 